УДК 539.374

\title{
Elastoplastic Bending of the Console with Transverse Force
}

\author{
Sergei I. Senashov* \\ Irina L. Savostyanova ${ }^{\dagger}$ \\ Reshetnev Siberian State University of Science and Technology \\ Krasnoyarskiy Rabochiy, 31, Krasnoyarsk, 660037 \\ Russia \\ Olga N. Cherepanova ${ }^{\ddagger}$ \\ Institute of Mathematics and Computer Science \\ Siberian Federal University \\ Svobodny, 79, Krasnoyarsk, 660041
}

Russia

\begin{abstract}
Received 10.05.2019, received in revised form 09.06.2019, accepted 20.07.2019
In the article an elastoplastic boundary for the console being bent with transverse force when the point of force is not situated in the centroid of transverse section was built with the use of the conservation laws. In this case bending moments and torques appear of the console. The case when the point of force is situated in the centroid of transverse section is considered in the previous works of the authors. In the work an infinite system of conservation laws has been built that allows us to reduce the problem of calculating elastoplastic boundary to a few quadratures, at the outer contour of transverse section. At that the contour can be random piecewise smooth. It is assumed that the lateral surface of the console is free from strains and is in its plastic condition.
\end{abstract}

Keywords: conservation laws, elastoplastic bending.

DOI: 10.17516/1997-1397-2019-12-5-637-643.

\section{Introduction}

Problems with unknown boundaries are ones of the most complex that appear when solving a number of continuum mechanics problems [1]. In the theory of plasticity to such a class belong problems that require building an elastoplastic boundary. The methods of building such boundaries, for some transverse sections, can be successfully solved with the use of the theory of functions of a complex variable methods and minimisation of functionals [2]. In the authors' works with the use of conservation laws it turned out well to build elastoplastic boundaries for rods, boundaries of which were random piecewise smooth contours [3]. Later it turned out that these methods could also be used to find elastoplastic boundaries in a console being bent.

In article [4] there is a solution for the problem of elastoplastic bending of the console with transverse force if the transverse force is applied to the centroid of transverse section. In this case only bending moments appear in the console. And if the transverse force is applied not to the centroid of transverse section then also torques appear in the console. This very case is considered in the suggested work.

\footnotetext{
*sen@sibsau.ru

$\dagger$ savostyanova@sibsau.ru

${ }^{\ddagger}$ cheronik@mail.ru

(c) Siberian Federal University. All rights reserved
} 


\section{Statement of a Problem}

Let us consider a straight console of constant section. Assume it is fixed in Section $Z=0$ and is loaded in its end section $Z=l$ with a force with resultant $\bar{P}=(P, 0,0)$. Let us situate the origin of coordinates on the fixed end, but we assume that it does not coincide with the centroid of the console's section. Also we assume that the console's lateral surface is free from strains and is in its plastic condition.

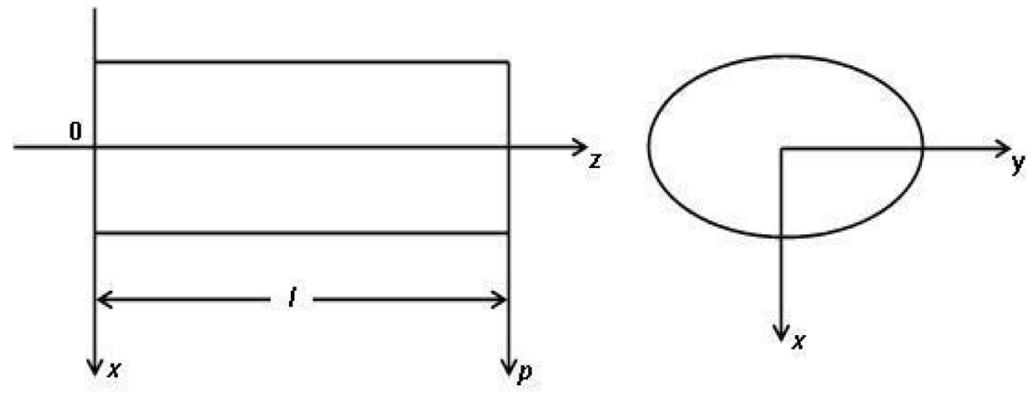

Fig. 1. Console

In this case [5] in elastic zone stress tensor components satisfy the equations

$$
\left\{\begin{array}{l}
F_{1}=\frac{\partial \tau_{x z}}{\partial x}+\frac{\partial \tau_{y z}}{\partial y}-P\left(\alpha_{1}\left(x-x_{C}\right)+\alpha_{2}\left(y-y_{C}\right)\right)=0 \\
F_{2}=\frac{\partial \tau_{x z}}{\partial y}-\frac{\partial \tau_{x z}}{\partial x}-\frac{1}{\mu}\left[K-\frac{P y}{2(1+v)}\left(\alpha_{2} x-\alpha_{1} y\right)\right]=0
\end{array}\right.
$$

Where $\left(x_{C}, y_{C}\right)$ - the coordinates of transverse section centroid,

$$
\begin{aligned}
& \alpha_{1}=\frac{I_{11} S-S_{1}^{2}}{\Delta}, \quad \alpha_{2}=\frac{I_{12} S-S_{1} S_{2}}{\Delta}, \\
& S=\iint d x d y, \quad S_{1}=\iint y d x d y, \quad S_{2}=\iint x d x d y, \\
& I_{11}=\iint y^{2} d x d y, \quad I_{12}=\iint x y d x d y, \quad I_{22}=\iint x^{2} d x d y, \\
& \Delta=\left(\begin{array}{ccccc}
I_{22} & I_{12} & S_{2} & & \\
I_{12} & I_{11} & S_{1} S_{2} & S_{1} & S
\end{array}\right) .
\end{aligned}
$$

Here $I_{i j}$ are moments of inertia, $S_{1}, S_{2}$ are static moments of inertia about Axes $x$ and $y ; \nu, \mu$ are elastic constants, $K=\frac{P y}{2(1+v)}\left(\alpha_{2} x_{C}-\alpha_{1} y_{C}\right)$.

As a result we will need to solve System of equations (1) with the following boundary conditions on Contour $\Gamma$ that limits the transverse section.

$$
\tau_{x z} l_{1}+\tau_{y z} l_{2}=0, \quad \tau_{x z}^{2}+\tau_{y z}^{2}=1
$$

Here $l_{1}, l_{2}$ are the normal's vector components to Contour $\Gamma$.

The first equation from (2) means that the lateral surface is free from strains and the second condition means that the lateral surface is in its plastic state. For simplicity of further calculations let us consider yield point at pure shear be equal to one. This can always be achieved with the help of introducing nondimensional variables. 
By reason of the above made assumptions - plastic strain range covers the entire lateral surface Fig. 2.

It is required to solve the following problem: determine the unknown boundary L taking into account the assumptions made.

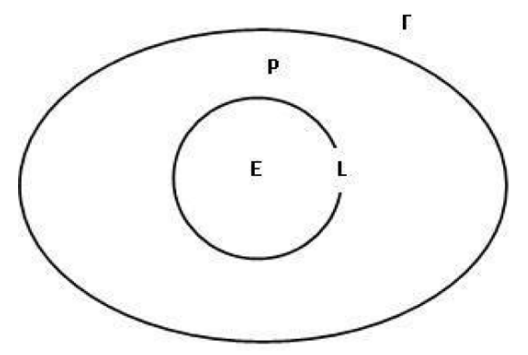

Fig. 2. $\mathrm{G}$ is the outer boundary, $\mathrm{L}$ is the elastoplastic boundary, $\mathrm{P}$ is the plastic deformation range, $\mathrm{E}$ is the elasticity deformation range

\section{Conservation laws}

Definition. Assume $F_{1}=0, F_{2}=0$, system of two differential equations (1) of two independent variables $x, y$. By conservation law the relation

$$
\partial_{x} A+\partial_{y} B=\Delta_{1} F_{1}+\Delta_{2} F_{2}=0
$$

is called that is fulfilled on all solutions of System $F_{1}=0, F_{2}=0$, Here $\Delta_{1}, \Delta_{2}$ are some linear differential operators. Vector $(A, B)$ is called conserved current.

Let us build conservation laws for System of equations (1).

We find conserved current in the form of

$$
A=a^{1} u+b^{1} v+\gamma^{1}, \quad B=a^{2} u+b^{2} v+\gamma^{2},
$$

where $\tau_{x z}=u, \tau_{y z}=v, a^{i}, b^{i}, \gamma^{i}$ are functions only $x, y$. Then the conservation law will be written as

$$
\partial_{x} A+\partial_{y} B=\omega_{1} F_{1}+\omega_{2} F_{2}=0 .
$$

In this case Operators $\Delta_{1}, \Delta_{2}$ reduce to multiplying by some functions of independent variables. Inserting (3) into (4) we obtain

$$
\begin{gathered}
a_{x}^{1} u+a^{1} u_{x}+b_{x}^{1} v+b^{1} v_{x}+\gamma_{x}^{1}+a_{y}^{2} u+a^{2} u_{y}+b_{y}^{2} v+b^{2} v_{y}+\gamma_{y}^{2}= \\
=\omega_{1}\left(u_{y}-v_{x}-f(x, y)\right)+\omega_{2}\left(u_{x}+v_{y}-g(x, y)\right) .
\end{gathered}
$$

Here by $f, g$ the right-hand sides of Equation (1) are shown.

Since Relation (5) is fulfilled identically, then all the coefficients at the required functions and their derivatives must be equal to zero. As a result we obtain

$$
a_{x}^{1}+a_{y}^{2}=0, \quad b_{x}^{1}+b_{y}^{2}=0, \quad a^{1}=\omega_{2}, \quad b^{1}=-\omega_{1}, \quad a^{2}=\omega_{2}, \quad b^{2}=\omega_{2}, \quad \gamma_{x}^{1}+\gamma_{y}^{2}=-\omega_{1} f-\omega_{2} g
$$

It follows

$$
a^{1}=b^{2}=\omega_{2}, \quad b^{1}=-a^{2}=-\omega_{1}, \quad a_{x}^{1}-b_{y}^{1}=0, \quad b_{x}^{1}+a_{y}^{1}=0 .
$$


In order to find $a^{1}, b^{1}$ it will be required to solve the equations

$$
a_{x}^{1}-b_{y}^{1}=0, \quad b_{x}^{1}+a_{y}^{1}=0 .
$$

From (6), in particular it follows that the system of equations being studied allows an infinite number of nontrivial conservation laws.

\section{Solution of Problem}

We will be finding two special solutions of Equations (6), i.e. such solutions that have a special feature in Point $x_{0}, y_{0}$.

The first solution of Equations (6), let us represent it as $a_{1}^{1}, b_{1}^{1}, \gamma_{1}^{1}, \gamma_{1}^{2}$ is written as:

$$
\begin{aligned}
& a_{1}^{1}=\left(y-y_{0}\right) /\left(\left(x-x_{0}\right)^{2}+\left(y-y_{0}\right)^{2}\right), \\
& b_{1}^{1}=\left(x-x_{0}\right) /\left(\left(x-x_{0}\right)^{2}+\left(y-y_{0}\right)^{2}\right), \\
& \frac{\partial \gamma_{1}^{1}}{\partial x}=b_{1}^{1} f-a_{1}^{1} g, \gamma_{1}^{2}=0 .
\end{aligned}
$$

From (7) we obtain

$$
\begin{aligned}
\gamma_{1}^{1} & =\alpha_{1} x+\frac{1}{2}\left(\alpha_{1}\left(x_{0}-x_{C}\right)-\frac{\left(y-y_{0}\right) \nu P \alpha_{2}}{2 \mu(1+\nu)}\right) \ln \left(\left(x-x_{0}\right)^{2}+\left(y-y_{0}\right)^{2}\right)+ \\
& +\left(\alpha_{2} \frac{y-y_{C}}{y-y_{0}}-\alpha_{1}\left(y-y_{0}\right)+\frac{K}{\mu}-\frac{\nu P}{2(1+\nu)}\left(\alpha_{2} x_{0}-\alpha_{1} y\right)\right) \operatorname{arctg} \frac{x-x_{0}}{y-y_{0}} .
\end{aligned}
$$

The second solution of Equations (6), let us represent it as $a_{2}^{1}, b_{2}^{1}, \gamma_{2}^{1}, \gamma_{2}^{2}$ is written as:

$$
\begin{aligned}
& a_{2}^{1}=-\left(x-x_{0}\right) /\left(\left(x-x_{0}\right)^{2}+\left(y-y_{0}\right)^{2}\right), \\
& b_{2}^{1}=\left(y-y_{0}\right) /\left(\left(x-x_{0}\right)^{2}+\left(y-y_{0}\right)^{2}\right), \\
& \frac{\partial \gamma_{2}^{1}}{\partial x}=b_{2}^{1} f-a_{2}^{1} g, \gamma_{2}^{2}=0 .
\end{aligned}
$$

From (9) we obtain

$$
\begin{aligned}
\gamma_{2}^{1}= & \frac{\alpha_{2} \nu P}{2(1+\nu) \mu} x+\frac{1}{2} P \alpha_{1}\left(y-y_{0}\right)- \\
& -\frac{1}{2 \mu}\left(K-\frac{\nu P \alpha_{2}}{(1+\nu)}\left(\alpha_{2} x_{0}-\alpha_{1} y\right)\right) \ln \left(\left(x-x_{0}\right)^{2}+\left(y-y_{0}\right)^{2}\right)+ \\
& +\left(P \alpha_{1}\left(x_{0}-x_{C}\right)+P \alpha_{2}\left(y-y_{C}\right)-\frac{\nu P \alpha_{2}}{2(1+\nu)}\left(y-y_{0}\right)\right) \operatorname{arctg} \frac{x-x_{0}}{y-y_{0}} .
\end{aligned}
$$

Let us convert the obtained conservation laws.

Conservation law (4) can be written using Green formula:

$$
\int_{\Gamma}\left(a^{1} u+b^{1} v+\gamma^{1}\right) d y-\left(-b^{1} u+a^{1} v+\gamma^{2}\right) d x=0,
$$

where $\Gamma$ is a random piecewise smooth contour. 
Assume $\left(x_{0}, y_{0}\right)$ - some points in the area covered by Contour $\Gamma$. Let us consider an ellipse inside of which there is Point $\left(x_{0}, y_{0}\right)$. Then we obtain see Fig. 3.

$$
\begin{gathered}
\int_{\Gamma}\left(a^{1} u+b^{1} v+\gamma^{1}\right) d y-\left(-b^{1} u+a^{1} v+\gamma^{2}\right) d x+\int_{\Gamma_{1}}+\int_{\Gamma_{2}}+ \\
\int_{\left(x-x_{0}\right)^{2}+k^{2}\left(y-y_{9}\right)^{2}=\varepsilon^{2}}\left(a^{1} u+b^{1} v+\gamma^{1}\right) d y+\left(-b^{1} u+a^{1} v+\gamma^{2}\right) d x=0 .
\end{gathered}
$$

Encirclement is carried out in such a way that the exceptional point stays outside the area covered by the contours. Since $\int_{\Gamma_{1}}+\int_{\Gamma_{2}}=0$, then we obtain

$$
\begin{aligned}
& \int_{\Gamma}\left(a^{1} u+b^{1} v+\gamma^{1}\right) d y-\left(-b^{1} u+\alpha^{1} v+\gamma^{2}\right) d x= \\
& =\int_{\Gamma_{1}}\left(a^{1} u+b^{1} v+\gamma^{1}\right) d y-\left(-b^{1} u+a^{1} v+\gamma^{2}\right) d x+ \\
& \quad+\int_{\Gamma_{2}}\left(a^{1} u+b^{1} v+\gamma^{1}\right) d y-\left(-b^{1} u+a^{1} v+\gamma^{2}\right) d x= \\
& =-\int_{\left(x-x_{0}\right)^{2}+k^{2}\left(y-y_{9}\right)^{2}=\varepsilon^{2}}\left(a^{1} u+b^{1} v+\gamma^{1}\right) d y+\left(-b^{1} u+a^{1} v+\gamma^{2}\right) d x .
\end{aligned}
$$

Here the integral in the right-hand side is calculated around the circle $O:\left(x-x_{0}\right)^{2}+\left(y-y_{0}\right)^{2}=\varepsilon^{2}$, in the centre of which there is an exceptional point.

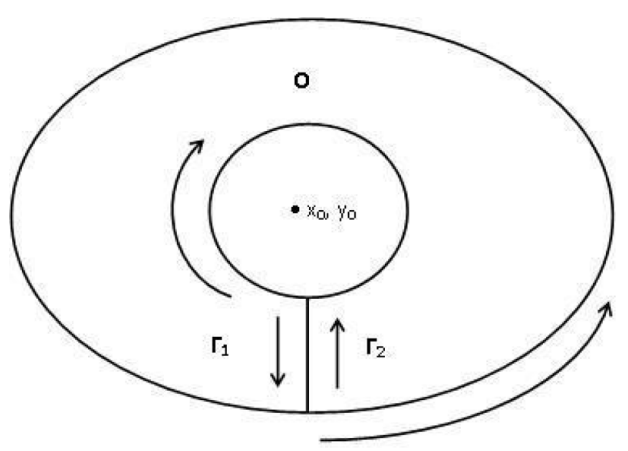

Fig. 3. Arrows show the direction of going around the boundaries

Assume $a^{1}=a_{1}^{1}, b^{1}=b_{1}^{1}$ from (7) we will calculate the integral in the right-hand side (11). We have

$$
-\int_{O}\left(a_{1}^{1} u+b_{1}^{1} v+\gamma_{1}^{1}\right) d y+\left(-b_{1}^{1} u+a_{1}^{1} v+\gamma^{2}\right) d x
$$

Assume $x-x_{0}=\varepsilon \sin \phi,\left(y-y_{0}\right)=\varepsilon \cos \phi$ then $a_{1}^{1}=\frac{\cos \phi}{\varepsilon}, b_{1}^{1}=\frac{\sin \phi}{\varepsilon}$ and expression (12) will be written as

$$
\begin{aligned}
& \int_{0}^{2 \pi}\left(\frac{\cos \phi}{\varepsilon} u+\frac{\sin \phi}{\varepsilon} v+\gamma^{1}\right) \varepsilon \sin \phi d \phi-\int_{0}^{2 \pi}\left(-\frac{\sin \phi}{\varepsilon} u+\frac{\cos \phi}{\varepsilon}+\gamma^{2}\right) \varepsilon \cos \phi d \phi= \\
& =\int_{0}^{2 \pi}\left(\left(-\cos ^{2} \phi+\sin ^{2} \phi\right) v+(\cos \phi \sin \phi+\cos \phi \sin \phi) u+\gamma^{1} \varepsilon \sin \phi-\gamma^{2} \varepsilon \cos \phi\right) d \phi= \\
& =-v\left(x_{0}, y_{0}\right) / 2 \int_{0}^{2 \pi} d \phi=-v\left(x_{0}, y_{0}\right) \pi
\end{aligned}
$$


For the development of this formula we sent and used the mean-value theorem. Hence

$$
\pi \mu\left(x_{0}, y_{0}\right)=-\int_{\Gamma}\left(a_{1}^{1} u+b_{1}^{1} v+\gamma_{1}^{1}\right) d y-\left(-b_{1}^{1} u+a_{1}^{1} v+\gamma_{1}^{2}\right) d x
$$

Let us now consider the second solution $a_{1}^{1}=a_{2}^{1}, b_{1}^{1}=-b_{2}^{1}$. Doing the same thing as in the first case we have

$$
\begin{aligned}
& -\int_{O}\left(a_{2}^{1} u+b_{2}^{1} v+\gamma_{2}^{1}\right) d y-\left(-b_{2}^{1} u+a_{2}^{1} v+\gamma_{2}^{2}\right) d x= \\
& =-\int_{O}\left(\frac{\left(x-x_{0}\right)}{r} u-\frac{\left(y-y_{0}\right)}{r} v+\gamma_{2}^{1}\right) d y-\left(\frac{\left(y-y_{0}\right)}{r} u+\frac{\left(x-x_{0}\right)}{r} v+\gamma_{2}^{2}\right) d x= \\
& =\int_{0}^{2 \pi}\left(\frac{\sin \phi}{\varepsilon} u-\frac{\cos \phi}{\varepsilon} v+\gamma_{2}^{1}\right) \varepsilon \sin \phi d \phi-\int_{0}^{2 \pi}\left(\frac{\cos \phi}{\varepsilon} u+\frac{\sin \phi}{\varepsilon} v+\gamma_{2}^{2}\right)(\cos \phi) \varepsilon d \phi= \\
& =\int_{0}^{2 \pi} u\left(-\cos ^{2} \phi+\sin ^{2} \phi\right) d \phi=-u\left(x_{0}, y_{0}\right) \pi .
\end{aligned}
$$

Finally we will get

$$
u\left(x_{0}, y_{0}\right)=\frac{1}{\pi} \int_{\Gamma}\left(a_{2}^{1} u+b_{2}^{1} v+\gamma_{2}^{1}\right) d y-\left(-b_{2}^{1} u+a_{2}^{1} v+\gamma_{2}^{2}\right) d x .
$$

Now the only thing remaining is to calculate the integral in the right-hand sides of Formulas (13), (14). For that we will use Formulas (2). They allow us to calculate $u=\tau_{x z}, v=\tau_{x z}$ on $\Gamma$. We have

$$
u l_{1}+v l_{2}=0, u^{2}+v^{2}=1
$$

From here we get expressions for $u=\tau_{x z}, v=\tau_{x z}$ on $\Gamma$

$$
\begin{gathered}
u=-\frac{l_{2}}{l_{1}} v,\left(\frac{l_{2}}{l_{1}}\right)^{2} v^{2}+v^{2}=1 . \\
v^{2}=\frac{l_{1}^{2}}{\left(l_{2}^{2}+l_{1}^{2}\right)}, \quad v= \pm \frac{l_{1}}{\sqrt{\left(l_{2}^{2}+l_{1}^{2}\right)}} . \\
u=\mp \frac{l_{2}}{\sqrt{\left(l_{2}^{2}+l_{1}^{2}\right)}} .
\end{gathered}
$$

In accordance with frontal moments, see Fig. 1, in Formulas (15) and (16) we choose the upper sign.

We insert (7)-(10) and (15), (16) into (13) and (14) and we find expressions for $u=\tau_{x z}$, $v=\tau_{x z}$ in all the points in the area limited by Contour $\Gamma$. This allows us to determine plastic and elastic zones. Those points where $\tau_{x z}^{2}+\tau_{y z}^{2}<1$ belong to elastic zone, and others fall into plastic zone. We point out that the solution of such a complex problem as building an unknown elastoplastic boundary has been reduced to calculating of a few quadratures.

\section{References}

[1] S.N.Antontsev, A.V.Kazhikhov, V.N.Monakhov, Bourdary Value Problems in Mechanises of Nonhomogeneous Fluids, North-Holland, 1990. 
[2] B.D.Annin, G.P.Cherepanov, Elastic-plastic problem, Novosibirsk, Nauka, 1983 (in Russian).

[3] S.I.Senashov, O.N.Cherepanova, A.V. Kondrin, About Elastoplastic torsion of rod, Vestnik SibGAU, 49(2013), no. 3, 100-103 (in Russian).

[4] S.I.Senashov, O.N.Cherepanova, A.V.Kondrin, Elastoplastic Bending of Beam, J. Sib. Fed. Univ., Math. and Physics., 7(2014), no. 2, 203-208.

[5] W.Nowacki, Theory of Asymmetric Elasticity, Berlin, N.Y. et al: Springer-Verlag, 1999.

\section{Упругопластический изгиб бруса поперечной силой}

Сергей И. Сенашов

Ирина Л. Савостьянова

Сибирский государственный университет науки и технологий им. Решетнева Красноярский рабочий, 31, Красноярск, 660037

Россия

Ольга Н. Черепанова

Институт математики и фундаментальной информатики

Сибирский федеральный университет

Свободный, 79, Красноярск, 660041

Россия

В статъе с помощъю законов сохранения построена упругопластическая граница для бруса, изгибаемого поперечной силой, когда точка приложения силь не лежит в центре тяжести поперечного сечения. В этом случае в стержне возникают изгибающие и крутящие моменты. Случай, когда точка приложения силь лежит в центре тяжести поперечного сечения, рассмотрен в предыдущих работах авторов. В работе построена бесконечная система законов сохранения, которая позволяет свести задачу вычисления упругопластичной границы к нескольким квадратурам, по внешнему контуру поперечного сечения. При этом контур может быть произвольным кусочно-гладким. Предполагается, что боковая поверхность бруса свободна от напряжений и находится в пластическом состоянии.

Ключевые слова: законы сохранения, упругопластический изгиб. 